
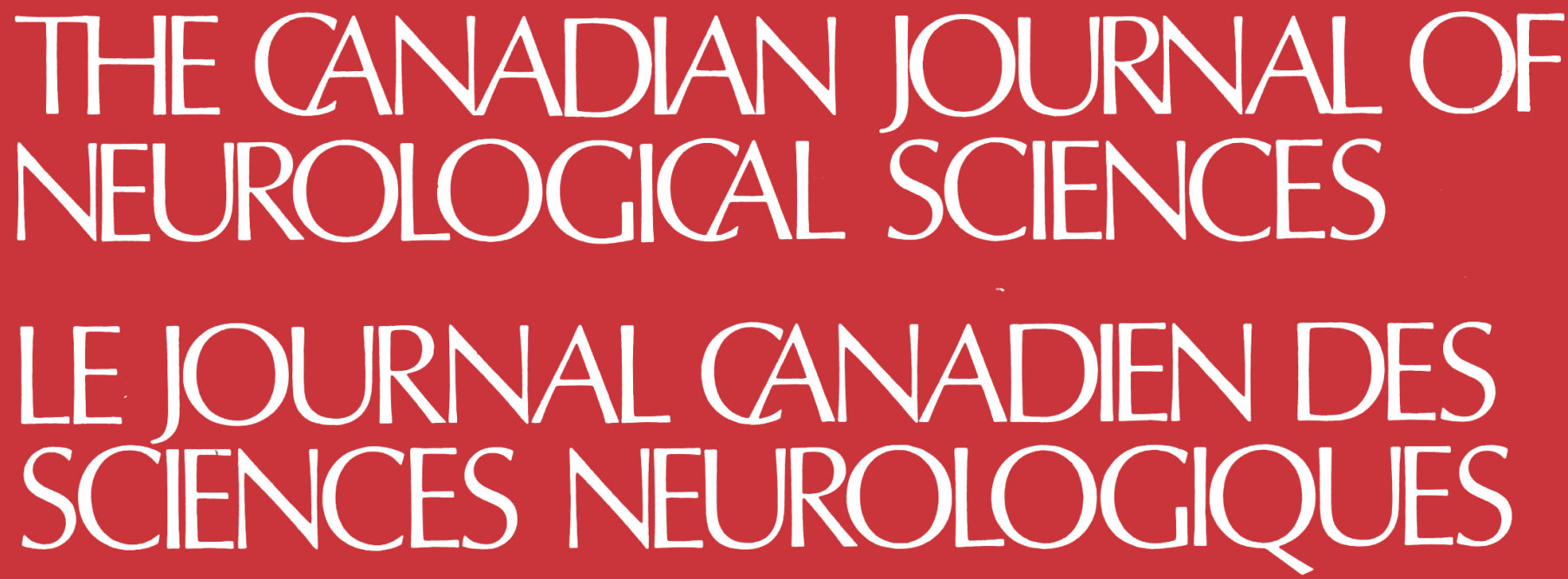

PRESIDENTIAL ADDRESS: XVII CANADIAN CONGRESS OF NEUROLOGICAL SCIENCES -

Cushing's Disease: 50 Years Later ................................. Jules Hardy

THE 1981 SILVERSIDES LECTURE — The Symptomatology of Tumours of the Anterior Visual Pathways

Percutaneous Localization of Conduction A bnormalities in Human Entrapment Neuropathies

Childhood Cerebral Cysticercosis:

Clinical Features and Computed Tomographic Findings

in 89 Mexican Children .................... Arturo López-Hernández and Carmen Garaizar

Clinical-Radiological Correlates in Intracerebral Hematomas due to

Aneurysmal Rupture ......... B.G. Benoit, D.D. Cochrane, F. Durity, G.G. Ferguson, D. Fewer. K.M. Hunter, M.I. Khan, G. Mohr, A.R. Watts, B.K.A. Weir and W.B. Wheelock

409

Multiple Sclerosis and Diabetes Mellitus:

Further Evidence of a Relationship Sharon A. Warren and K.G. Warren

Distribution of Dopamine in 35 Subregions of the Rat Caudate-Putamen:

A High Performance Liquid Chromatography with Electrochemical

Detection Analysis ..................... Thérèse Di Paolo, Michel Daigle and André Dupont

Auditory Brainstem Response Abnormalities

in Autistic Children M.J. Taylor, B. Rosenblatt and L. Linschoten

Valproic Acid Producing a Reye-Like Syndrome

D.L. Keene, P. Humphreys, B. Carpenter and J.P. Fletcher

435

Spino-Cerebello-Cerebral Degeneration with Amyloid Plaques

(Gerstmann, Sträussler, Scheinker Syndrome) ................. C.L. Dolman and L.L. Daly

439

Respiratory Arrest and Cervical Spinal Cord Infarction

Following Lumbar Puncture in Meningitis ...

Margaret G. Norman

443

SUBJECT REVIEW: Adrenoleukodystrophy Brian P. O'Neill and Hugo W. Moser

Announcements

Book Reviews

461

Index to Volume 9 - 1982

\title{
Ofificial Journal of
}

The Canadian Neurological Sociely

The Canadian Neurosurgieal Sociely 


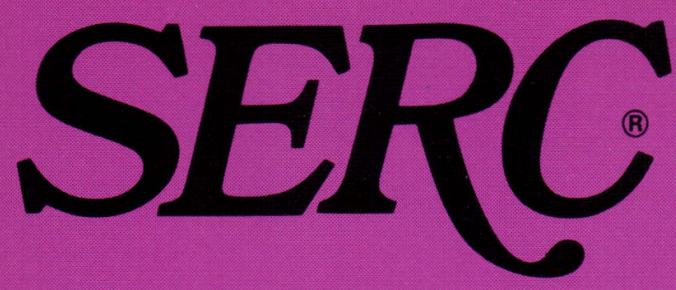

(betahistine hydrochloride tablets)

\section{For the management of Vertigo}

\section{- Proven efficacy}

"(Serc) is now a proven, useful therapeutic agent in the treatment of Ménière's disease, especially in the control of vertigo."

\section{- Restores vestibular responses}

"In a preliminary trial (Wilmot 1971) using objective testing of both auditory and vestibular function,...the results showed statistical significance in favour of Serc."

\section{- Reduced severity of episodic vertigo}

"... a significant improvement in favour of the drug (Serc) with regard to vertigo, tinnitus and deafness. Vertigo was the most responsive symptom."

\section{- Well tolerated}

"No adverse reactions were observed."

\section{REFERENCES}

1Frew, I.J.C. et al. Postgrad. Med. J. 52:501-503, 1976.

2Wimot, TJ. et al: J. Laryng. Otol; 9.833-840, 1976

PRESCRIBING INFORMATION INDICATIONS: SERC may be of value in reducing the episodes of vertigo in Meniere's disease. No claim is made for the effectiveness of SERC in the symptomatic treatment of any form of vertigo other than that associated with Meniere's disease.

DOSAGE AND ADMINISTRATION: The usual adult dosage has been one to two tablets ( $4 \mathrm{mg}$. each) administered orally three times a day.

Recommended starting dose is two tablets three times daily. Therapy is then adjusted as needed to maintain patient response. The dosage has ranged from two palient response. The dosage has ranged from two tablets per day to eight tablets per day. No more than eight tablets are recommended to be taken in any one day.

SERC (betahistine hydrochloride) is not recommended for use in children. As with all drugs, SERC should be kept out of reach of children.

CONTRAINDICATIONS: Several patients with a history of peptic ulcer have experienced an exacerbation of symptoms while using SERC. Although no causua relation has been established SERC is contraindicated in the presence of peptic ulcer and in patients with a history of this condition. SERC is also contraindicated in patients with pheochromocytoma.

PRECAUTIONS: Although clinical intolerance to SERC by patients with bronchial asthma has not been demonstrated, caution should be exercised if the drug is used in these patients.

USE IN PREGNANCY: The safety of SERC in pregnancy has not been established. Therefore, its use in pregnancy or lactation, or in women of childbearing age requires that its potential benefits be weighed against the possible risks.

ADVERSE REACTIONS: Occasional patients have ex perienced gastric upset, nausea and headache

HOW SUPPLIED: Scored tablets of $4 \mathrm{mg}$ each in bottles of 100 tablets

Full prescribing information available on request.

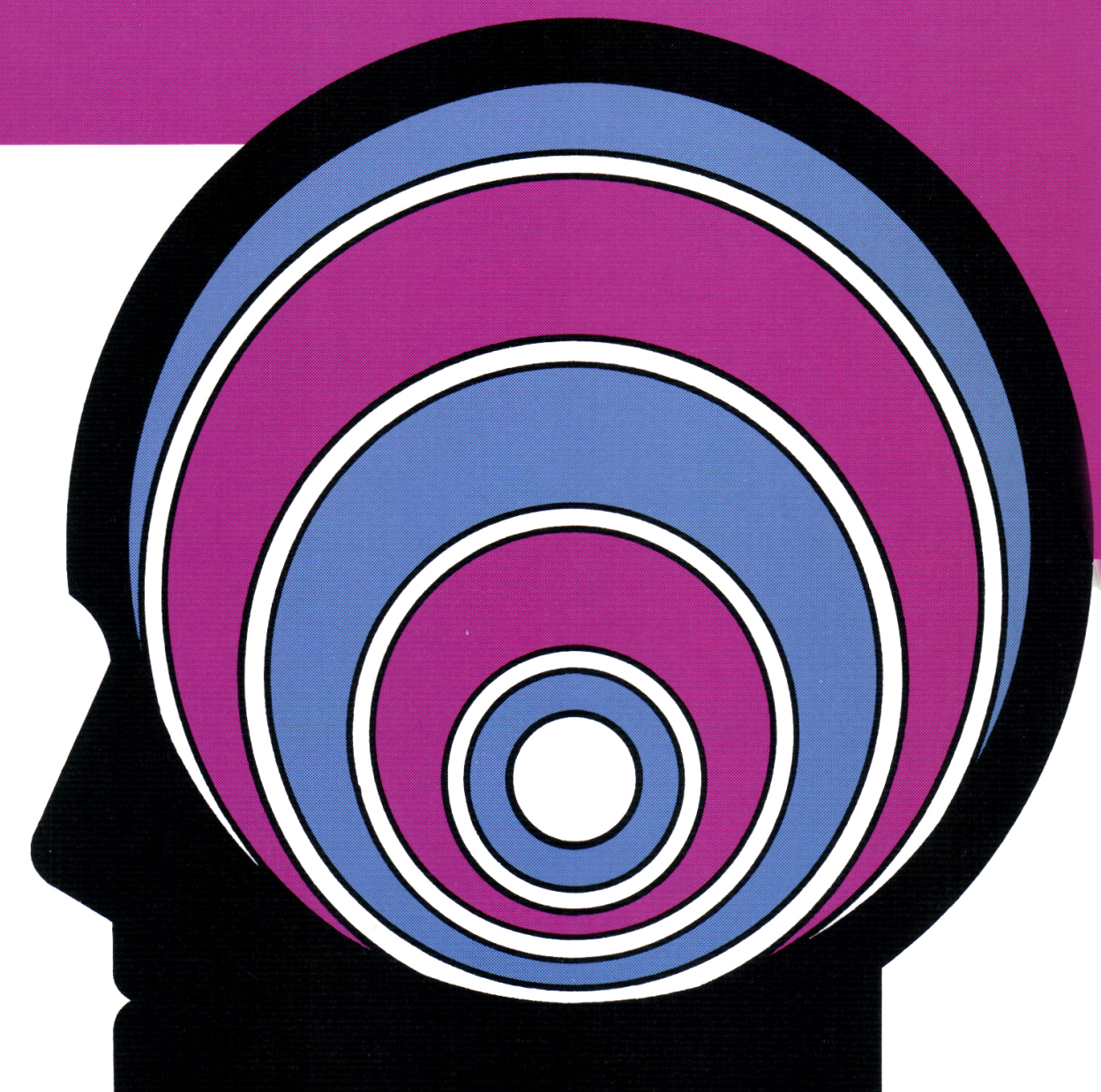



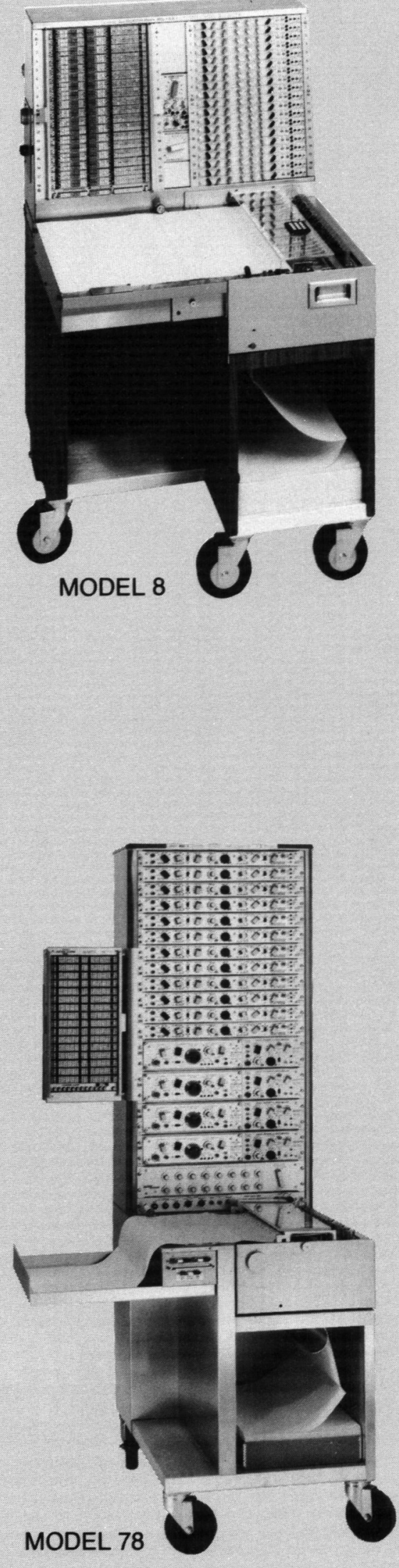

\section{POLYSOMNOGRAPHIC RECORDING FOR CLINIC OR RESEARCH}

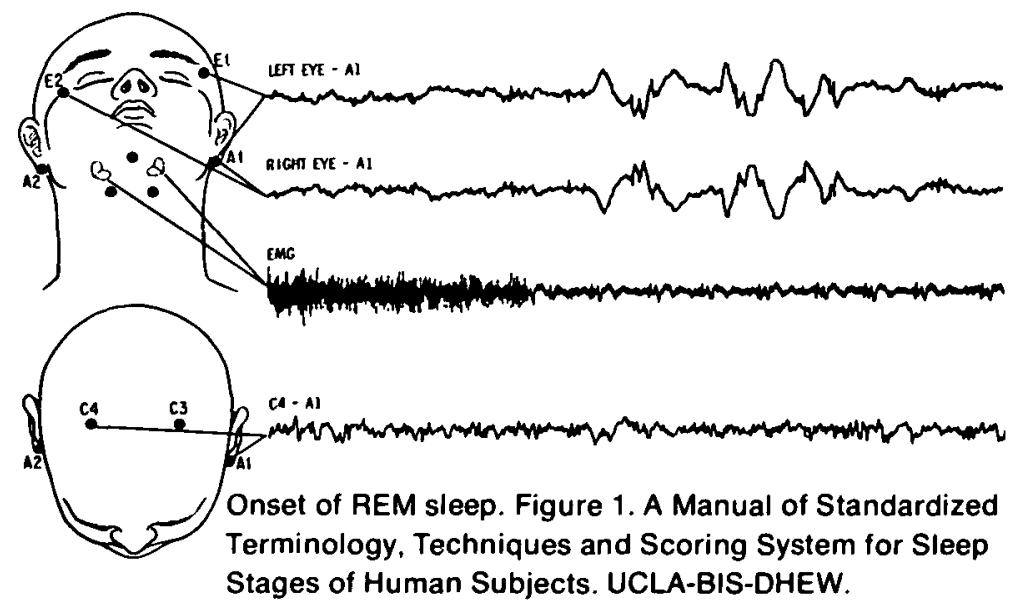

For multiple parameter recording of sleep-wake disorders in the clinical or the research setting, Grass Polygraphs and EEGs have the reliability and flexibility required.

For research applications, the Model 78 Polygraph with a wide selection of interchangeable signal conditioning preamplifiers allows recording several channels of EEG, EOG, EMG, ENG, temperature, respiration, EKG, blood gases, etc., with convenience and ease. A wide range of transducers, recording accessories, plus muttiple chart speeds, including the widely used $10 \mathrm{~mm} / \mathrm{sec}$, provide a complete sleep-wake recording system.

For dual purpose applications where the primary interest is in clinical EEG and the secondary interest involves multiple parameter sleep studies, the Model 8 EEG is the instrument of choice.

For dependable long-term studies - rely on Grass, recording bioelectric activity since 1935 .

Write for further information on a system to meet your polysomnographic recording needs.

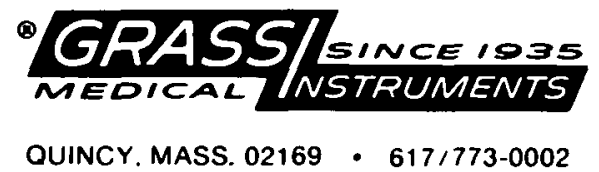

D139H78

(A) GRASS IHSTRUMENT CO. 1978 


\section{Stop most headaches in just 30 minutes}

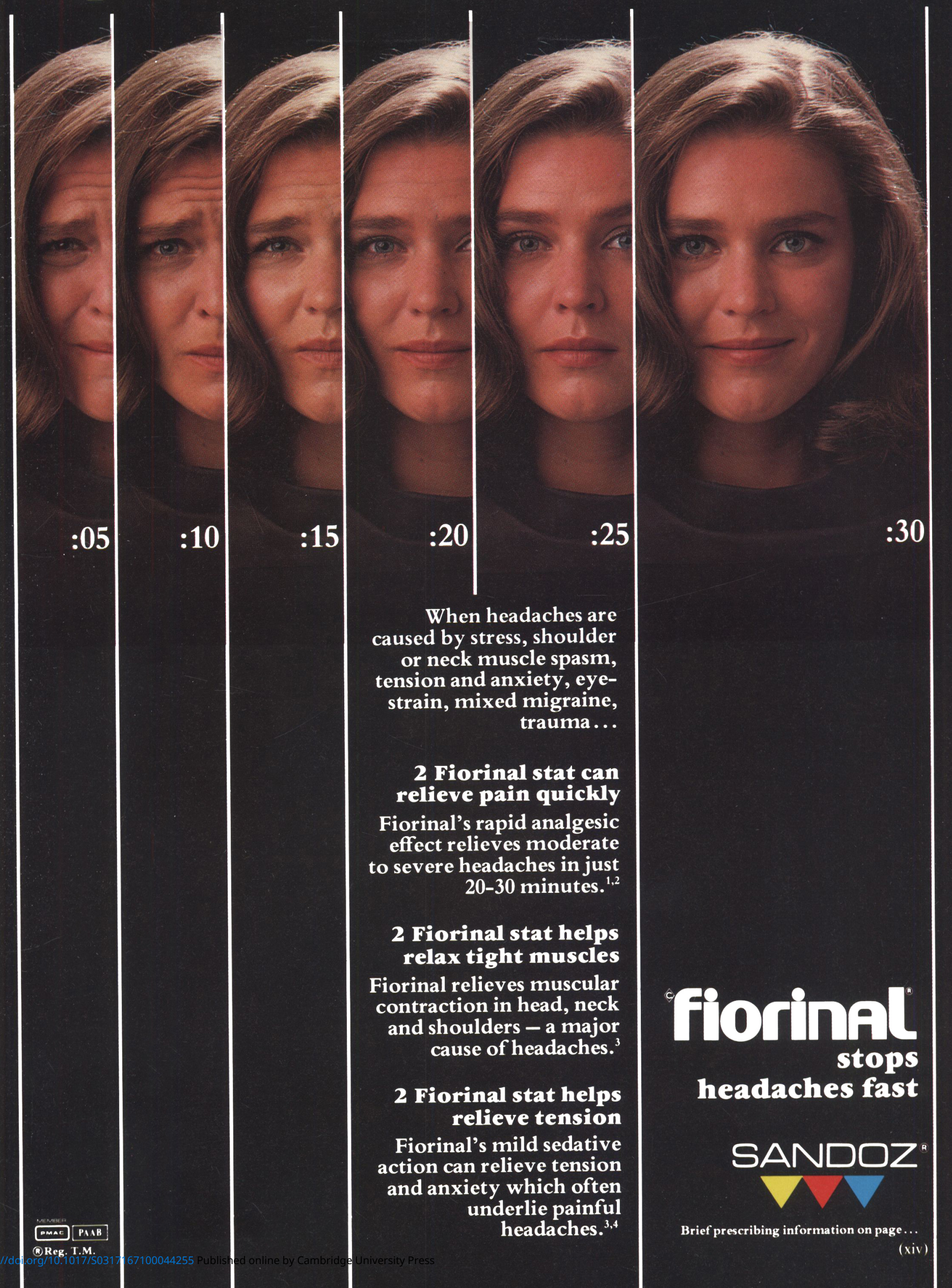




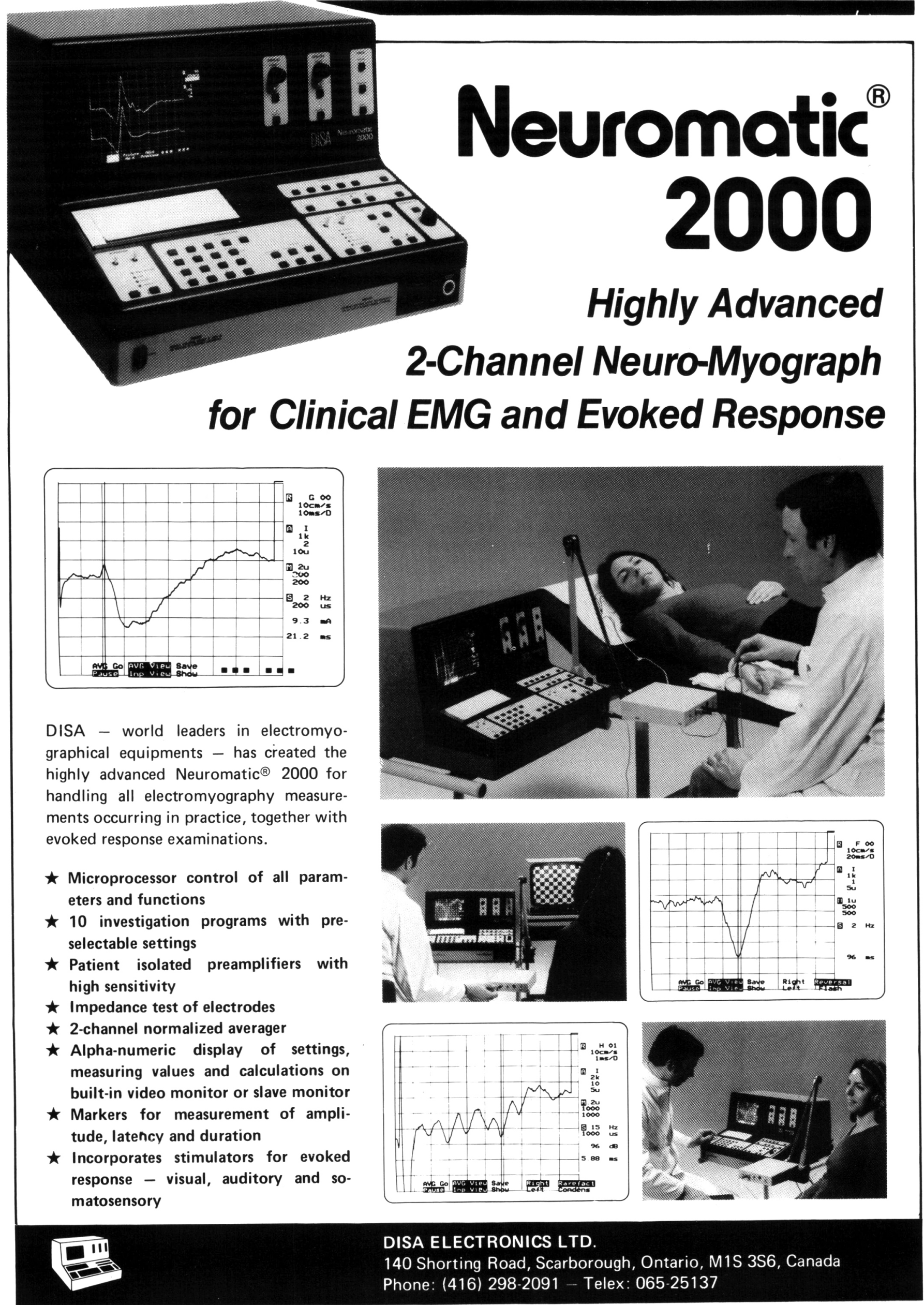




\section{Editor}

Robert G. Lee

Calgary

\section{Editorial Board}

Albert J. Aguayo

Montreal

Henry J.M. Barnett

London

Paul Bédard

Quebec

Henry B. Dinsdale

Kingston

Guy Geoffroy

Montreal

Alan Hudson

Toronto

Yves Lamarre

Montreal

\section{News Editor}

\section{Arthur J. Hudson}

London

THE EDITORIAL BOARD wishes to publish original work in the basic and clinical neurosciences on the understanding that it has not been and will not be published elsewhere. Review articles on timely subjects will be accepted. Manuscripts must be in triplicate including illustrations. One of the copies must be the original, ribbon copy. Manuscripts should be typed double spaced, on white paper.

Papers will be accepted in French or English. All papers should be accompanied by a short résumé in both languages. The résumé translation will be done by the editorial board if requested.

Papers should be identified only by the full name of the author, or authors, and the name of the place in which the work was done.

ILLUSTRATIONS: Photographs should be unmounted on glossy paper and show magnification scale. They should be marked on the back with figure number, title of paper and name of author.

Diagrams should be in India ink and large enough to be informative after reduction.

All illustrations should be referred to as figures, numbered consecutively, not included in the body of the text and all captions should be typed on a separate piece of paper.

\author{
Associate Editor \\ André Barbeau \\ Montreal
}

Bernard Lemieux

Sherbrooke

William J. Logan

Toronto

Morton Low

Vancouver

Thomas P. Morley

Toronto

Thomas J. Murray

Halifax

Donald Paty

Vancouver

Sidney J. Peerless

London

Colored illustrations cannot usually be accepted unless the author is prepared to assist with the cost of reproduction.

REFERENCES to authors outside the context of the sentence should read (Name, Year). i.e. "However, a recent study (Bird and Iverson, 1975) showed a decreased, etc." Authors mentioned within the context of the sentence should read Name (Year), "i.e. ... twenty years since Ecker and Reimenshender (1951) demonstrated, etc." References should be typed in alphabetical order on a separate sheet and include author's name, initials, year, tithe, publication, volume first and last page, i.e. Isacson, P. (1967). Myx-oviruses and autoimmunity. Progress in $\mathrm{Al}-$ lergy, 10, 256-292. Abbreviations should be the same as those used in Cumulated Index Medicus.

Textbook references should include name of text, author's name, page number, publisher and city.

REPRINTS: Fifty reprints will be supplied free if ordered when the galley proofs are returned. More may be ordered at a nominal charge. Corrections and changes in the galley proofs, apart from printer's errors may be charged to the author.

This journal is indexed by Index
Founding Editor

Robert T. Ross

Winnipeg

Terry Picton

Ottawa

Jean Reiher

Sherbrooke

Leo P. Renaud

Montreal

Barry Rewcastle

Calgary

Matthew W. Spence

Halifax

William G. Tatton

Tororito

Bryce Weir

Edmonton

\section{Editorial Assistant}

Lucile G. Edwards

Calgary

Medicus, Excerpta Medica and Current Contents - Clinical Practice and Life Science.

SUBSCRIPTIONS: This journal is issued four times a year. The annual rate is $\$ 32.00$ for Canada and the U.S.A. $\$ 34.00$ elsewhere. Internes, Residents, Preand Post-Doctoral Students, $\$ 16.00$ per annum. Single copies $\$ 10.00$ each.

ADVERTISING: Enquiries regarding advertising space and rates should be directed to LEX LTD. VANCO PUBLICATIONS, 190 Main Street, Unionville, Ontario L3R 2G9. Telephone - (416) 297-2030.

All communications, manuscripts, subscriptions, etc., should be sent to the Editor, Canadian Journal of Neurological Sciences, Faculty of Medicine, 2500 University Drive, Calgary, Alberta, Canada T2N 1 N4.

COPYRIGHT 1982 by THE CANADIAN JOURNAL OF NEUROLOGICAL SCIENCES INC. No part of this journal may be reproduced in any form without the prior permission of The Canadian Journal of Neurological Sciences.

Printed by Lawson Graphics Ltd., 708 Moray Street

Winnipeg, Manitoba R3J 359.

Mailed under second class registration number 3307 . Postage paid at Winnipeg, Manitoba. 
PUBLICATIONS COMMITTEE

Donald Baxter

Montreal
Andrew Eisen

Vancouver
Terry Myles

Calgary

\section{CANADIAN NEUROLOGICAL SOCIETY}

President

Past-President

Vice-President

Secretary-Treasurer
Thomas J. Murray

Henry B. Dinsdale

Robert F. Nelson

Garth M. Bray

1650 Cedar Avenue

Montreal, P.Q.

H3G 1 A4
Council:

Monique d'Amour

Michel Drolet

John Humphrey

Andrew Kertesz

Ali Rajput

Peter Seland

\section{CANADIAN NEUROSURGICAL SOCIETY}

President

Past-President

President-Elect

Secretary-Treasurer
Stuart Huestis

Jules Hardy

Leslie Ivan

Gary Ferguson

University Hospital

London, Ontario

N6A 5A5
Council:

Jacques Boucher

Derek Fewer

Robin Humphreys

Fala Maroun

Andre Olivier

Barry Purves

\section{CANADIAN SOCIETY OF CLINICAL NEUROPHYSIOLOGISTS \\ President \\ Past-President \\ Secretary-Treasurer \\ Warren Blume \\ Andrew Eisen \\ Terry Picton \\ Ottawa General Hospital \\ 501 Chemin Smythe Road \\ Ottawa K1H 8L6 \\ Council: \\ Roger Broughton \\ Reda El-Sawy \\ Normand Giard \\ Leroy Heffernan \\ Sherrill Purves}

\section{CANADIAN ASSOCIATION FOR CHILD NEUROLOGY \\ President \\ Past President \\ Vice-President \\ Secretary-Treasurer \\ Rosalind Curtis \\ Warren Blume \\ Fred Andermann \\ Jean Gibson \\ I.W. Killam Hospital \\ P.O. Box 3070 \\ Halifax, Nova Scotia B3J 3G9 \\ Council: \\ Peter Camfield \\ Shashikant Seshia \\ Simon Verrett}




\section{you wouldn't guess Jane's an epileptic}

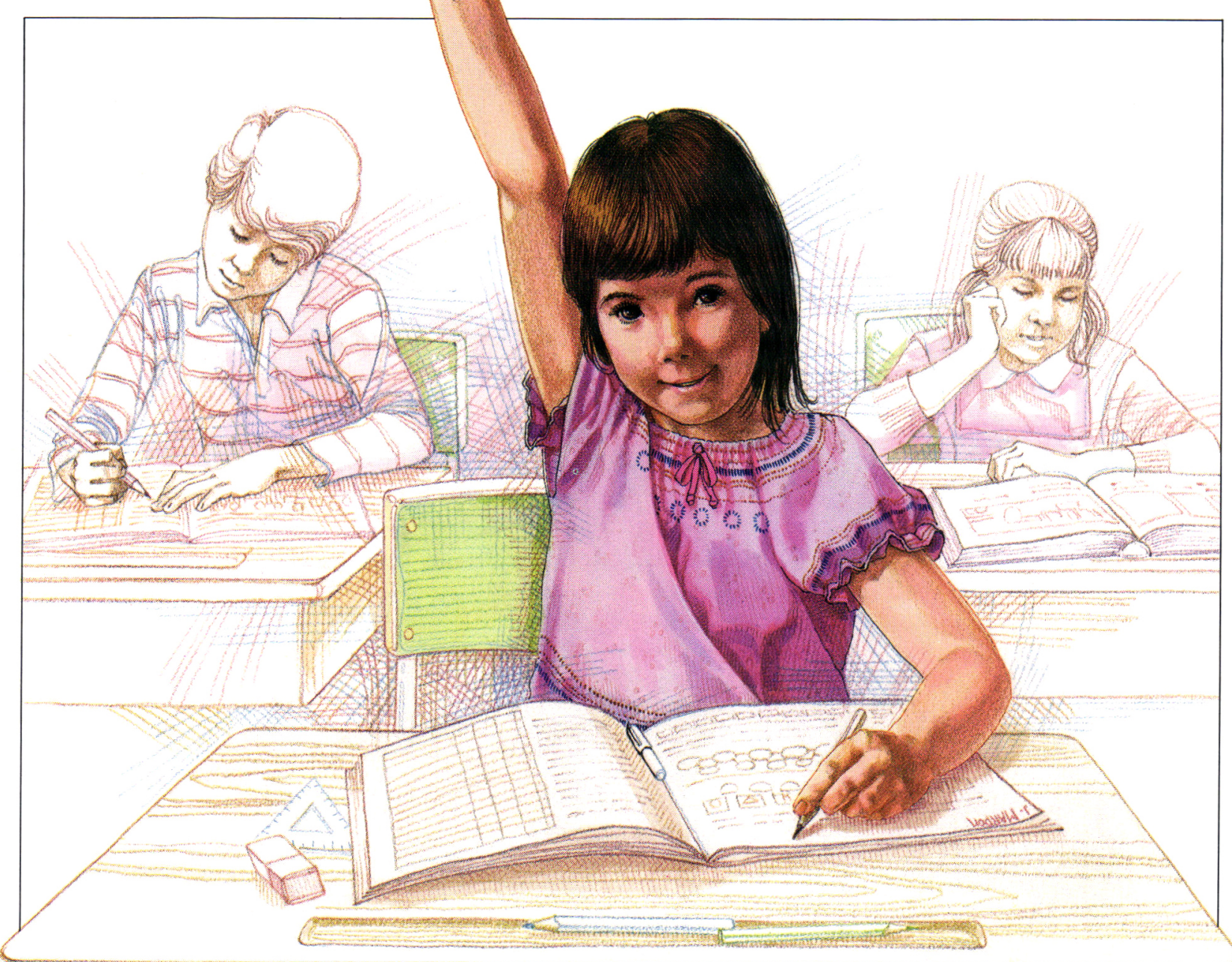

Epileptic therapy doesn't have to interfere with her life. Depakene can effectively control seizures, with little risk of disturbed behaviour or poor performance.

Depakene provides broad-spectrum seizure control Depakene is considered a drug of first choice for simple and complex absence seizures 1,2 and has been successfully used in tonic-clonic or myoclonic seizures with absence components. ${ }^{3,4}$

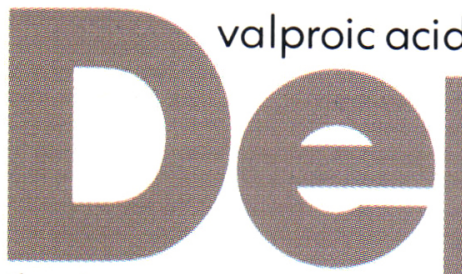
brings many
No impairment of learning Depakene has made patients more alert, more lively and better able to perform daily tasks. ${ }^{5}$

Positive effect on behaviour

Depakene, unlike phenobarbital, rarely affects behaviour, and may actually improve it. ${ }^{5}$
Low incidence of disturbing side effects Depakene does not cause hirsutism, gum hyperplasia or acne, nor has it been associated with aplastic anemia or agranulocytopenia.

Minimizes problems of

polypharmacy Depakene is often effective as single therapy. When other anticonvulsants are necessary, their dosage may be reduced.

New dosage convenience A 500-mg enteric-coated capsule is now available.
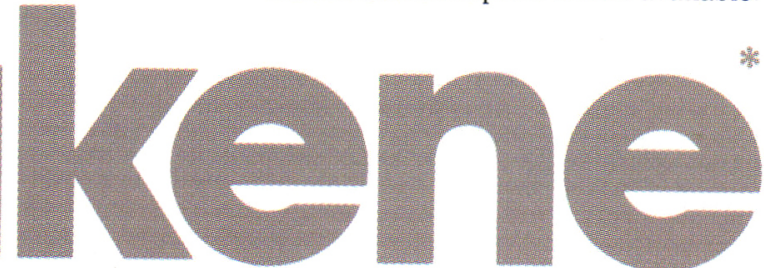
epileptic patients closer to normal 


\section{Brief prescribing information}

INDICATIONS AND CLINICAL USE: Depakene (valproic acid) is indicated for use as sole and adjunctive therapy in the treatment of simple and complex absence seizures, including which include absence.

In accordance with the International Classification of Seizures, simple absence is defined as a very brief clouding of the sensorium or loss of consciousness (lasting usually 2-15 seconds) accompanied by certain generalized epileptic discharges without other detectable clinical signs. Complex absence is the term used when other signs are also present.

CONTRAINDICATIONS: Depakene (valproic acid) should not be administered to patients with hepatic disease or significant dysfunction; it is contraindicated in patients with known hypersensitivity to the drug.

WARNINGS: Hepatic failure resulting in fatalities has occurred in patients receiving Depakene. These incidences usually have occurred during the first six months of treatment with Depakene. Serious or fatal hepatotoxicity may be preceded by non-specific symptoms such as loss of seizure control, malaise, weakness, lethargy, anorexia and vomiting. Patients and parents should be instructed to report such symptoms. Because of the nonspecific naty inwell, of ther than through obvious causes while taking sodium val proate.

Liver function tests should be performed prior to therapy and at frequent intervals thereafter Liver especially during the first six months. However, physicans should not rely totally on serum lochems the results of carefulinision observed when administering Depakene to patients with a prior history of hepatic disease. accompanied by mental particular risk.

In high-risk patients, it might also be useful to monitor serum fibrinogen and albumin for decrease in concentrations and serum ammonia for increases in concentration. If changes occur, valproic acid should be discontinued. Dosage should be titrated to and maintained at the lowest dose consistent with optimal seizure control.

The drug should be discontinued immediately in the presence of significant hepatic dysfunctions, suspected or apparent. In some cases, hepatic dysfunction has progressed in spite of discontinuation of drug. The frequency of adverse effects particularly elevated liver enzymes may increase with increasing dose. Ther efore, the benefit gained by increased seizure control by increasing the dosage must be weighed against the increased incidence of adverse effects sometimes seen at higher dosages.

USE IN PREGNANCY: The safety of Depakene (valproic acid) during pregnancy has not we physician should weigh the potential benefits against the possible riss in treating or counselling women of childbearing age who have epilepsy.

ef anticonvulsant drugs and an

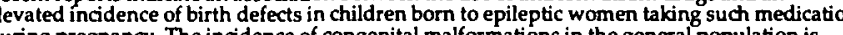


egarded the approximately $2 \%$, in children or treated epileptic women, this incidence may malformations of the heart, and cleft lip and/or palate. Nevertheless, the great majority of malformations of the heart, and cleft lip and/or palate. Nevertheless,

Data are more extensive with respect to diphenylhydantoin and phenobarbital, but these drugs are also the most commonly prescribed anticonvulsants. Some reports indicate Pe use other anticonvulsant rimethadione and paramethadione. However, the possibility also exists that other factors, e.g. genetic predisposition or the epileptic condition itself may contribute to or may be mainly

patients to whom the drug is administered to prevent major seizures, because of the strong possibility of precipitating tatus epilepticus with attendant hypoxia and risks to both the mother and the unborn child. or regard drugs given for minor seizures, the risks of discontinuing medication prior to case and with the particular family history.

Epileptic women of child-bearing age should be encouraged to seek the counsel of their physician and should report the onset of pregnancy promptly to him. Where the necessity for indicated.

NURSING MOTHERS: Depakene is secreted in breast milk. Concentrations in breast milk have been reported to be 1 to $10 \%$ of serum concentrations. As a general rule, nursing should

FER TILITY: Chronic toxicity studies in juvenile and adult rats and dogs demonstrated reduced spermatogenesis and testicular atrophy at doses greater than $200 \mathrm{mg} / \mathrm{kg} /$ day in rats and $90 \mathrm{mg} / \mathrm{kg} /$ day in dogs. Segment I fertility studies in rats have shown that doses up to 350
$\mathrm{mg} / \mathrm{kg} / \mathrm{day}$ for 60 days have no effect on fertility. The effect of Depakene (valproic acid) on the development of the testes and on sperm production and fertility in humans is unknown. LONG TERM TOXICITY

PRECAUTIONS: HEPATIC DYSFUNCTION: SEE CONTRAINDICATIONS AND WARNINGS

GENERAL: Because of reports of thrombocytopenia and platelet aggregation dysfunction, platelet counts and bleeding-time determination are recommended before instituting therapy and at periodic intervals. It is recommended that patients receiving Depakene (valproic acid) be monitored for platelet count prior to planned surgery. Clinical evidence of hemorrhage, bruising or a disorder of hemostasis/coagulation is an indication for reduction of Depaken (valproic acid) dosage or withdrawal of therapy pending investigation.

Hyperammonemia with or without lethargy or coma has been reported and may be present in the absence of abnormal liver function tests; if elevation occurs, the valproic acid should be discontinued.

Because Depakene (valproic acid) may interact with other anticonvulsant drugs, periodic serum level determinations of such other anticonvulsants are recommended during the early part of therapy (see DRUC INTERACTIONS). There have been reports of breakthrough eizures occurning with the combination of Depakene and phenytoin.

Depakene (valproic acid) is partially eliminated in the urine as a ketone-containing metabolite which may lead to a false interpretation of the urine ketone test.

DRIVING AND HAZARDOUS OCCUPATIONS: Valproic acid may produce CNS

depression, especially when combined with another CNS depressant, such as alcohol. Therefore, patents should be advised not to engage in hazardous occupations, such as driving a car or operating dangerous machinery, until it is known that they do not become drowsy from the drug.

DRUG INTERACTIONS: DEPAKENE (VALPROIC ACID) MAY POTENTIATE THE CNS TT ACTION OF ALCOHOL

THERE IS EVIDENCE THAT VALPROIC ACID MAY CAUSE AN INCREASE IN SERUM PHENOBARBITAL LEVELS, ALTHOUGH THE MECHANISM IS UNKNOWN, PATIENTS RECEIVING CONCOMTANT BARBITURATE THERAPY SHOULD BE CLOSELY SHOULD BE OBTAINED, IF POSSIBLE, AND THE BARBITURATE DOSAGE DECREASED, IF INDICATED.
Primidone is metabolized into a barbiturate, and therefore, may also be involved in a similar THERE IS CONFL ICTING EVIDENCE REGARDING THE INTERACTON OF VALPROIC ACID WITH PHENYTOIN. IT IS NOT KNOWN IF THERE IS A OHANGE INUNBOUND (FREE) PHENYTOIN SERUM LEVES. THE DOSE OF PHENYTOIN SHOULD BE ADJUSTED AS REQUIRED BY THE CLINICAL SITUATION.
THE CONCOMTTANT USE OF VALPROIC ACID AND CONAZEPAM MAY PRODUCE ABSENCE STATUS.

Caution is recommended when valproic acid is administered with drugs affecting acetyisalicylic acid and warfarin (see ADVERSE REACTIONS).

ADVERSE REACTIONS: The most commonly reported adverse reactions are nausea vomiting and indigestion. Since Depakene (val proic acid) has usually been used with other mentioned in this section are due to valproic acid alone or to the combination of drugs. GASTROINTESTINAL: Nausea, vomiting and indigestion are the most commonly reparted side effects at the initiation of therapy. These effects are usually transient and rarely requin reported. Anoreda with some weight loss and increased appetite with some weight gain have reported. Anored

CNS EFFECTS: Sedative effects have been noted in patients receiving valproic acid alone but are found most often in patients on combination therapy. Sedation usually disappears upon reduction of other anticonvulsant medication. Ataxia, headache, nystagmus, diplopia, asterixis, "spots before the eyes", tremor, dysarthria, dizziness, and incoondination have rarely been noted. Rare cases of coma have been reported in patients who were also on phenobarbital.

DERMATOLOGIC: Transient increases in hair loss have been observed. Skin rash and petechiae have rarely been noted.

ENDOCRINE: There have been reports of irregular menses and secondary amenorthea in patients receiving Depakene. PSYCHIATRIC: Emotional upset, depression, psychosis, aggression, hyperactivity and
behavioural deterioration have been reported.

MUSCULOSKELETAL: Weakness has been reparted.

HEMATOPOIETIC: Thrombocytopenia has been reported. Valproic acid inhibits the second phase of platelet aggregation (see DRUG INTERACTIONS). This may be reflected in altered bleeding time. Bruising, hematoma formation and frank hemorthage have been reported. Relative lymphocytosis and hypofibrin

HEPATIC: Minor elevations of transaminases (e.g. SGOT and SGPT) and LDH are frequen and appear to be dose-related. Occasionally, laboratory tests also show increases in serum potentially serious hepatotoxicity. (See WARNINGS)

METABOLIC: Hyperammonemia. (See PRECAUTIONS). Hyperglycinemia has been reported and associated with a fatal outcome in a patient with pre-existing nonketotic hyperglycinemia.

PANCREATIC: Isolated reports of pancreatitis in association with valproic acid therapy have been received.

SYMPTOMS AND TREATMENT OF OVERDOSAGE: In a reported case of overdosage with

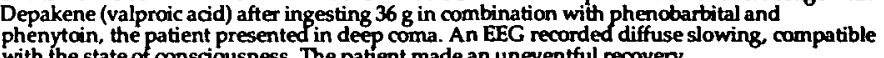
with the state of consciousness. The patient made an uneventful recovery. Naloxone has been reported to reverse the CNS depressant effects of Depakene overdose. chould be used with caution.

As valproic acid is absorbed very rapidly, gastric lavage may be of timited value General supportive measures should be applied with particular attention to the prevention of hypovolemia and the maintenance of adequate urinary output.

DOSAGE AND ADMINISTRATION: Depakene (valproic acid) is administered orally. The recommended initial dose is $15 \mathrm{mg} / \mathrm{kg} /$ day, increasing at one-week intervals by 5 to

$\mathrm{mg} / \mathrm{kg} /$ day until seizures are controlled or side effects predude further increases. The maximal recommended dose is $60 \mathrm{mg} / \mathrm{kg} /$ day. When the total daily dose exceeds $250 \mathrm{mg}$. 250-mg capsules.

The frequency of adverse effects (particularly elevated liver enzymes) may increase with increasing dose. Therefore, the benefit gained by increased seizure control must be weighed
against the increased incidence of adverse effects. Table of Initial Doses by Weight (based on $15 \mathrm{mg} / \mathrm{kg} /$ day)

\begin{tabular}{cccccc}
\hline Kg & Weight & lb & $\begin{array}{c}\text { Total Daily } \\
\text { Dose (mg) }\end{array}$ & \multicolumn{2}{c}{$\begin{array}{c}\text { Number of Capsules or } \\
\text { Teaspoonfuls of Symup } \\
\text { Dose 1 } \\
\text { Dose 2 }\end{array}$} \\
\hline $10-24.9$ & $22-54.9$ & 250 & 0 & 0 & 1 \\
Dose 3 & \\
\hline $25-39.9$ & $55-87.9$ & 500 & 1 & 0 & 1 \\
$40-59.9$ & $88-131.9$ & 750 & 1 & 1 & 1 \\
$60-74.9$ & $132-164.9$ & 1,000 & 1 & 1 & 2 \\
$75-89.9$ & $165-197.9$ & 1,250 & 2 & 1 & 2 \\
\hline
\end{tabular}

As the dosage of valproic acid is raised, blood levels of phenobarbital and/or phenytoin may be affected (see PRECAUTIONS).

Patients who experience G.I. irritation may benefit from administration of the drug with food or by a progressive increase of the dose from an initial low level. Such patients may benefit from administration of the enteric-coated capsule. The capsing
chewing to avoid local irritation of the mouth and throat. AVAILABILITY: Depakene (valproic acid) is available as orange-coloured, soft-gelatin
capsules of $250 \mathrm{mg}$ in bottles of $100 \mathrm{capsules}$ (Number 5681 ; DIN 443840); pale yelow, oval soft gelatin enteric-coated capsules of 500 ng in bottes of 100 capsules $(N$ mar 0795 ; DiN salt, per $5 \mathrm{~mL}$ in bottles of $450 \mathrm{~mL}$ (Number 5682; DIN 443832).

Depakene is now available in a 500 -mg enteric-coated capsule.

REFERENCES:

1. BMJ editorial, March 3, 1979.

3. Jeavons PM et al: Treatment of generalized epilepsies of childhood and adolescence with sodium valproate. Dev Med Child Neurol 1977; 19: 9-25.

4. Wilder B]: Valproic acid in clinical use: An overview. Proceedings of the Valproic Acid

Round Table Conference, June 1978, Vancouver. Excerpta Medica 1979

5. Coulter DL et al: Valproic acid in childhood epilepsy. JAMA 1980; 244 (8): 785-88.
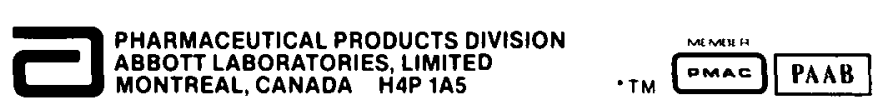
PRESIDENTIAL ADDRESS: XVII CANADIAN CONGRESS OF NEUROLOGICAL SCIENCES -

Cushing's Disease: 50 Years Later - Jules Hardy

THE 1981 SILVERSIDES LECTURE - The Symptomatology of Tumours of the Anterior Visual Pathways W.I. McDonald

Percutaneous Localization of Conduction Abnormalities in Human Entrapment Neuropathies W.F. Brown and S.K. Yates.

Childhood Cerebral Cysticercosis: Clinical Features and Computed Tomographic Findings in 89 Mexican Children - Arturo López-Hernández and Carmen Garaizar

Clinical-Radiological Correlates in Intracerebral Hematomas due to Aneurysmal Rupture B.G. Benoit, D.D. Cochrane, F. Durity, G.G. Ferguson, D. Fewer, K.M. Hunter, M.I. Khan, G. Mohr, A.R. Watts, B.K.A. Weir and W.B. Wheelock

Multiple Sclerosis and Diabetes Mellitus: Further Evidence of a Relationship Sharon A. Warren and K.G. Warren

Distribution of Dopamine in 35 Subregions of the Rat Caudate-Putamen:

A High Performance Liquid Chromatography with Electrochemical Detection Analysis Thérèse Di Paolo, Michel Daigle and André Dupont

Auditory Brainstem Response Abnormalities in Autistic Children

M.J. Taylor, B. Rosenblatt and L. Linschoten

Valproic Acid Producing a Reye-Like Syndrome

D.L. Keene, P. Humphreys, B. Carpenter and J.P. Fletcher

Spino-Cerebello-Cerebral Degeneration with Amyloid Plaques

(Gerstmann, Sträussler, Scheinker Syndrome)

C.L. Dolman and L.L. Daly.

Respiratory Arrest and Cervical Spinal Cord Infarction Following Lumbar Puncture in Meningitis Margaret G. Norman

SUBJECT REVIEW: Adrenoleukodystrophy - Brian P. O'Neill and Hugo W. Moser 449

HISTORICAL VIEWPOINT: The Neurology of Alice in Wonderland

T.J. Murray

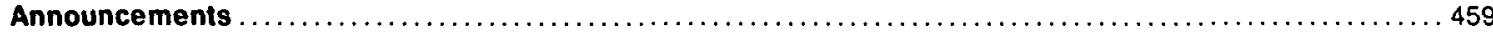

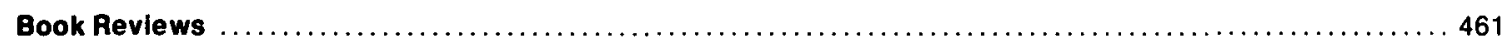

Index to Volume 9 - 1982.

(i) 


\section{Mobile, stable and optically}

unicue: Surcical operating microscopes of the Wild M600 Series.

The brand-new concepts of the WILD Surgical Operating Microscopes offer decisive advantages for microsurgery.

- See more with the refined optical system

\section{- Position comfortably}

with the articulated, balanced modular design

- Work confidently with the rugged, stable stand and the sterilisable controls

- Expand individually for photography, cine and TV without special modifications

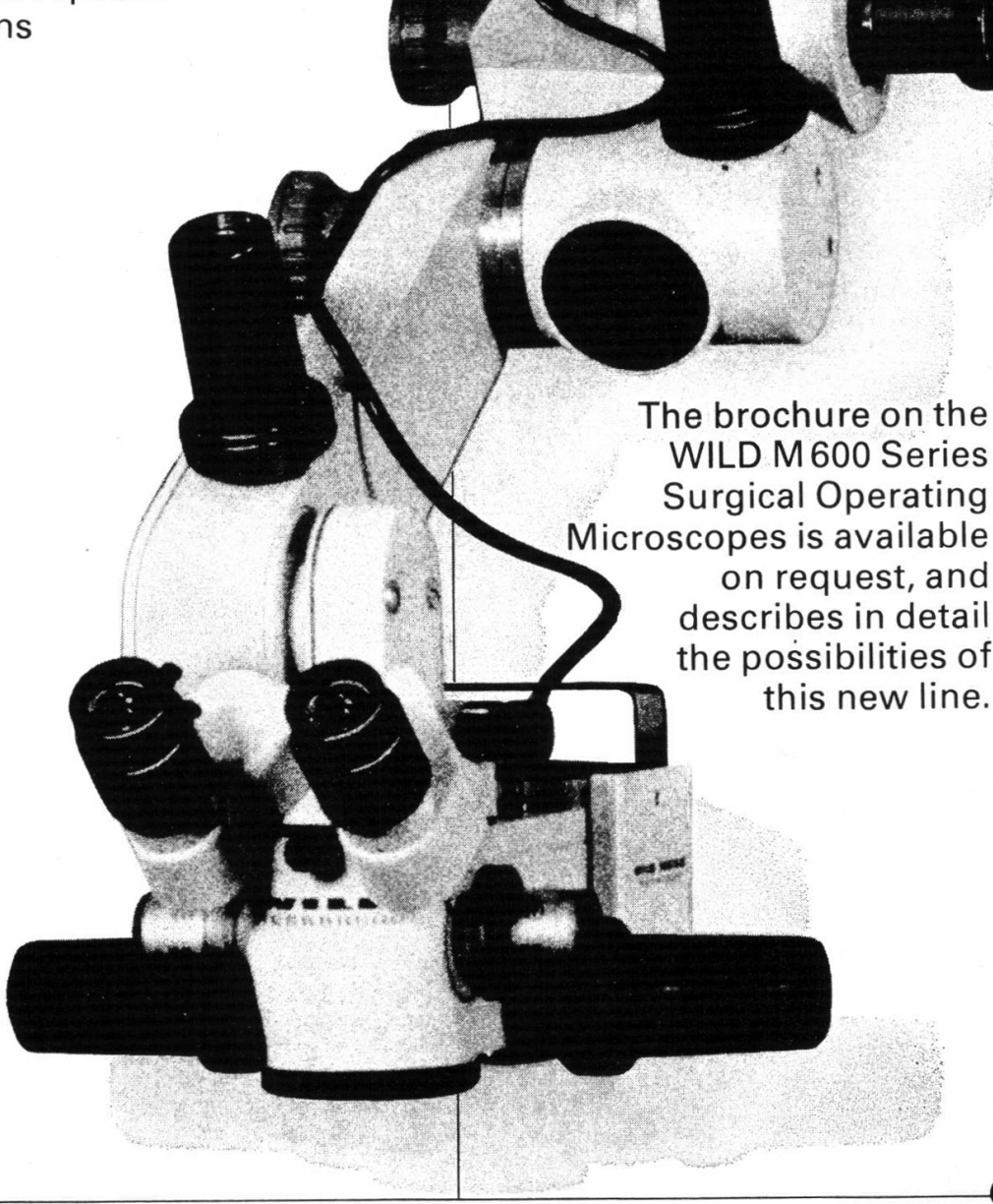




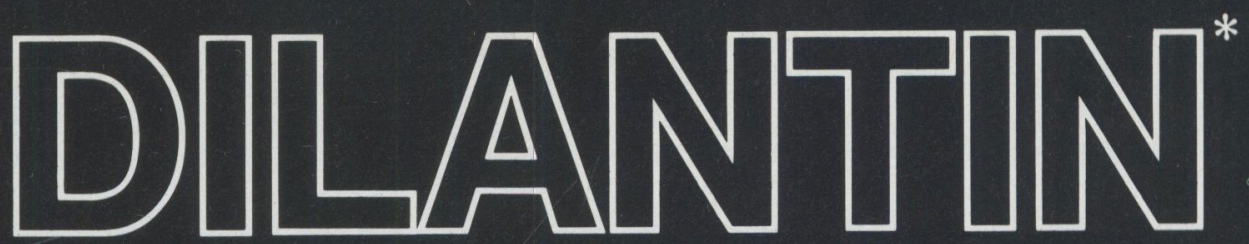

\section{Extended Phenytoin Sodium Capsules U.S.P. A RECOGNIZED DIFFERENCE}

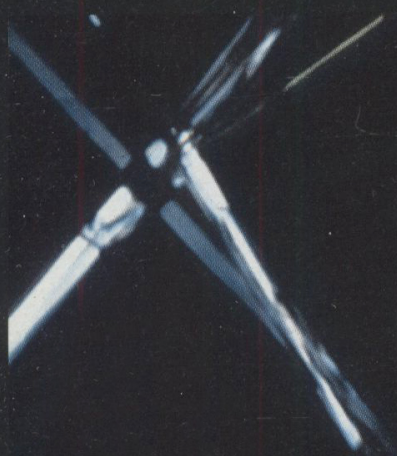

\section{USP XX now differentiates between Extended and Prompt Phenytoin Sodium Capsules.}

Extended phenytoin sodium has been recognized as a distinct pharmaceutical entity. Its slow dissolution and absorption do not create significant fluctuations in phenytoin blood levels.
Prompt phenytoin sodium has a faster dissolution and higher initial blood levels. The two forms of phenytoin sodium are not interchangeable. ${ }^{\star \star}$

\section{DILANTIN Capsules have not changed.}

Extended effect has always been the action of DILANTIN therapy. Only the U.S.P. standards have changed to recognize the difference between "extended" and "prompt" phenytoin sodium. Both you and your patient can continue to benefit from the consistent antiepileptic action of DILANTIN capsules.

\section{Once-daily-dosage option is confirmed for DILANTIN Capsules.}

Extended action of DILANTIN offers greater convenience and improved patient compliance Dependable, effective therapy is now available through a oncedaily-dosage option, once seizure control has been established with divided doses.

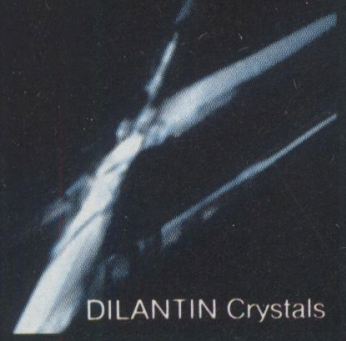

DILANTIN formulation ensures dependable bioavailability.

Extended phenytoin classification of DILANTIN capsules is the result of its unique dissolution profile. Due to its special formulation, DILANTIN exerts a slow, steady release of phenytoin for dependable bioavailability.

**Patients should be maintained on one form of phenytoin (extended

or prompt) to avoid toxicity or loss of seizure control.

\section{START WITH DILANTIN-STAY WITH DILANTIN FOR OVER A GENERATION, THE STANDARD IN EPILEPSY MANAGEMENT}




\section{INDEX TO ADVERTISEMENTS}

\author{
Abbott Laboratories, Depakane - (vi) and (vii) \\ DISA - (iii) \\ Geigy, Tegretol - inside back cover, (xii) and (xxiv) \\ Geigy, Lioresal - outside back cover, (xxiii) \\ Grass Instruments, \\ Polysomnographic Recording (i)
}

Heerbrugg Microscopes - (ix)

Parke Davis, Dilantin, Zarontin - (x) and (xi)

Sandoz, Fiorinal - (ii) and (xxii)

Sandoz, Sandomigran - (xiii) and (xxii)

Unimed Canada, Serc - inside front cover
How doyou spell truth in advertising?

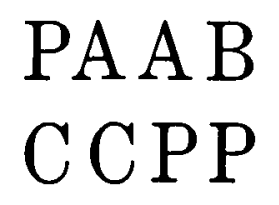

This logo appearing on pharmacoutical edvertisemente in protesalonal foumals means that the advertisementa have maceutical Advertising Advlsory Board/Consall Coneutati de Publlelie Pharmaceutique.

This unique screening systom for pharmacoutical adventis. Ing is the first of its kind in North Americe. The Board of Directore ts composed of indlviduals ropresenting the following orgenlzations. . Acsoclation des tabricants du

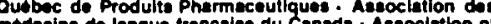

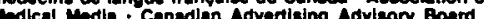

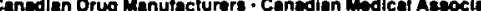
Ilon - Canedian Pharmeceutical Association . Consumers Aseociation of Canada. Pharmaceutical Manufacturer Asecciation of Canodia.

The Hoalth Protection Branch of Hoatth and Woitare Caned acts as advieor and resource body to the board.

The program onsures the accuracy of pharmeceutical edvertialng to the hallth professions. so that it may continus

\section{BRIEF PRESCRIBING INFORMATION

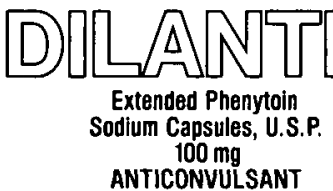

INDICATIONS

Dilantin is indicated for the control of generalized tonic-clonic (grand mal) seizures and complex partial (psychomotor) seizures.

\section{CONTRAINDICATIONS}

Dilantin is contraindicated in those patients with a history of hypersensitivity to hydantoin products.

\section{WARNINGS}

Abrupt withdrawal of phenytoin in epileptic patients may precipitate status epilepticus. Phenytoin is not indicated in seizures due to hypoglycemia or other causes which may be immediately identified and corrected. Phenytoin metabolism may be significantly altered by the concomitant use of other drugs such as:

A Barbiturates may enhance the rate of metabolism of phenytoin. This effect, how ever, is variable and unpredictable. It has been reported that in some patients the concomitant administration of carbamazepine resulted in an increased rate of phenytoin metabolism.

B Coumarin anticoagulants, disulfiram, phenylbutazone, and sulfaphenazole may in hibit the metabolism of phenytoin, resulting in increased serum levels of the drug. This may lead to an increased incidence of nys tagmus, ataxia, or other toxic signs.

C Isoniazid inhibits the metabotism of phenytoin so that with combined therapy, patients who are slow acetylators may suffer from phenytoin intoxication.

D Tricyclic antidepressants in high doses may precipitate seizures, and the dosage of phenytoin may have to be adjusted accordingly.

Usage in Pregnancy: The effects of Dilantin in human pregnancy and nursing infants are unknown.

The prescribing physician will have to determine the risk/benefit in treating or counselling epileptic women of childbearing potential.

\section{PRECAUTIONS}

The liver is the chief site of biotransformation of phenytoin, patients with impaired liver function may show early signs of toxicity. Elderly patients or those who are gravely ill may show early signs of toxicity.

A small percentage of individuals who have been treated with phenytoin have been shown to metabolize the drug slowly. Slow metabolism may be due to limited enzyme availability and lack of induction; it appears to be genetically determined.

Phenytoin has been associated with reversible lymph node hyperplasia. If lymph node enlargement occurs in patients on phenytoin, every effort should be made to substitute another anticonvulsant drug or drug combination.

Drugs that control generalized tonic-clonic (grand mal) seizures are not effective for absence (petit mal) seizures. Therefore, if both conditions are present, combined drug therapy is needed.

Hyperglycemia, resulting from the drug's inhibitory effect on insulin release, has been reported. Phenytoin may also raise the blood sugar level in persons already suffering from hyperglycemia.

\section{ADVERSE REACTIONS}

Central Nervous System: The most common manifestations encountered with phenytoin therapy include nystagmus, ataxia, slurred speech, and mental confusion. Dizziness, insomnia, transient nervousness, motor twitchings, and headache have also been observed. These side effects may disappear with continuing therapy at a reduced dosage level.

Gastrointestinal System: Phenytoin may cause nausea vomiting and constipation. Administration of the drug with of immediately after meals may help prevent gastrointestinal discomfort

Integumentary System: Dermatological manifestations sometimes accompanied by fever have included scarlatiniform or morbilliform rashes.

Hemopoietic System: Hemopoietic complications, some fatal have occasionally been reported in association with administration of phenytoin. These have included thrombocytopenia, leukopenia, granulocytopenia, agranulocytosis, and pancytopenia.

Other: Gingival hyperplasia occurs frequently; this incidence may be reduced by good oral hygiene including gum massage frequent brushing and appropriate denta care. Polyarthropathy and hirsutism occur occasionally. Hyperglycemia has been reported. Toxic hepatitis, liver damage, and periarteritis nodosa may occur and can be latal.

\section{MANAGEMENT OF OVERDOSAGE}

The mean lethal dose in adults is estimated to be 2 to 5 grams. The cardinal initial symptoms are hystagmus, ataxia and dys arthria. The patient then becomes comatose, the pupils are unresponsive and hypotension occurs. Death is due to respiratory depression and apnea. Treatment is nonspecific since there is no known antidote. First the stomach should be emptied. If the gag reflex is absent, the airway should be supported. Oxyoen, vasopressors and as sisted ventilation may be necessary for central nervous system, respiratory and cardiovascular depression. Finally, hemodialysis can be considered since phenytoin is not completely bound to plasma proteins. DOSAGE AND ADMINISTRATION

Dosage should be individualized to provide maximum benefit. In some cases, serum blood level determinations may be necessary for optimal dosage adjustments - the clinically effective serum level is usually $10-20 \mathrm{mcg} / \mathrm{mL}$.

Adult Dose: Patients who have received no previous treatment may be started on one $100 \mathrm{mg}$ Dilantin Capsule three times daily and the dose then adjusted to suit individual requirements.

Pediatric Dose: Initially, $5 \mathrm{mg} / \mathrm{kg} /$ day in two or three equally divided doses, with subsequent dosage individualized to a maximum of $300 \mathrm{mg}$ daily. A recommended daily maintenance dosage is usually 4 to $8 \mathrm{mg} / \mathrm{kg}$. Children over 6 years old may require the minimum adult dose ( $300 \mathrm{mg} /$ day). Pediatric dosage forms available include a $30 \mathrm{mg}$ Capsule, a $50 \mathrm{mg}$ palatably flavoured Infatab, or an oral suspension form containing $30 \mathrm{mg}$ of Dilantin in each $5 \mathrm{~mL}$.

Alternative Dose: Once-a-day dosage for adults with $300 \mathrm{mo}$ of Dilantin may be considered if seizure control is established with divided doses of three $100 \mathrm{mg}$ Capsules daily.

HOW SUPPLIED

Dilantin $100 \mathrm{mg}$ Capsules; in bottles of $100 \& 1000$.

Complete prescribing information available upon request.

\section{PARKE-DAVIS}

Parke-Davis Canada Inc. Scarborough, Ontanio

Reg. T.M. Parke Davis \& Company Parke-Davis Canada Inc., auth. user 


\section{inthe efíctive}
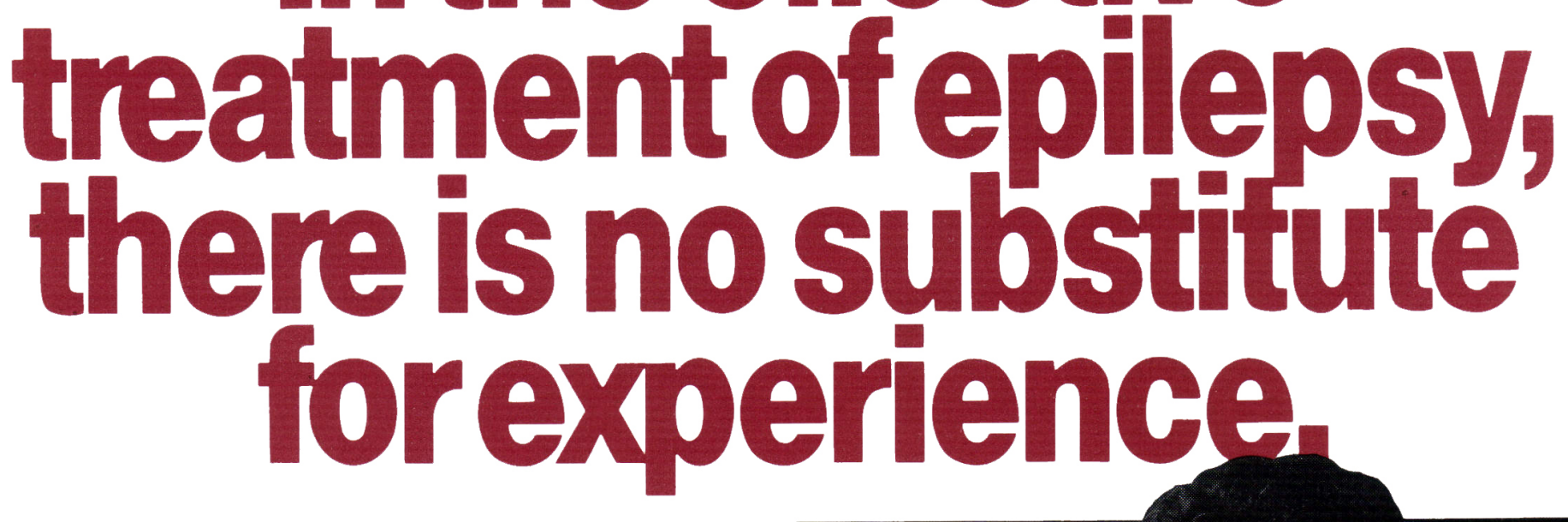

The original carbamazepine, TEGRETOL ${ }^{\circledR}$, was first introduced by Geigy in 1969 and subsequently became the drug of choice for trigeminal neuralgia.

But this development marked only the beginning.

Geigy research soon provided the basis for approval in the treatment of psychomotor/ temporal lobe epilepsy in 1973.

And in 1979, this indication was again expanded to include usage in refractory generalized tonic/clonic seizures.

This committment to the ongoing potential of TEGRETOL does not end here: continuing research indicates that further applications are possible in the future.

While the provision of a quality pharmaceutical is a primary objective of Geigy, other services to both doctor and patient have not gone unaddressed.

Medical information, support to continuing medical education and attention to the needs of epileptic patients, their families and Associations have been important elements in the overall attention given to this disorder.

In fact, a prescription for TEGRETOL does farmore in the fight against epilepsy than just control patient symptoms.

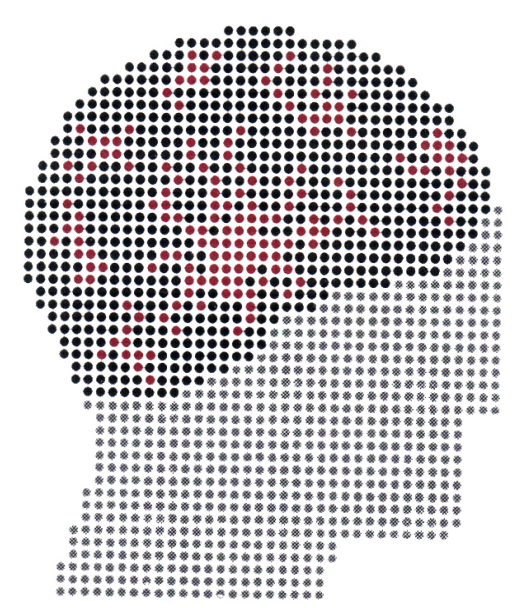

No Substitution.

Because there is no substitute for experience. Yours, or ours.

\section{Geigy \\ Mississauga, Ontario L5N 2W5


Help prevent recurrent

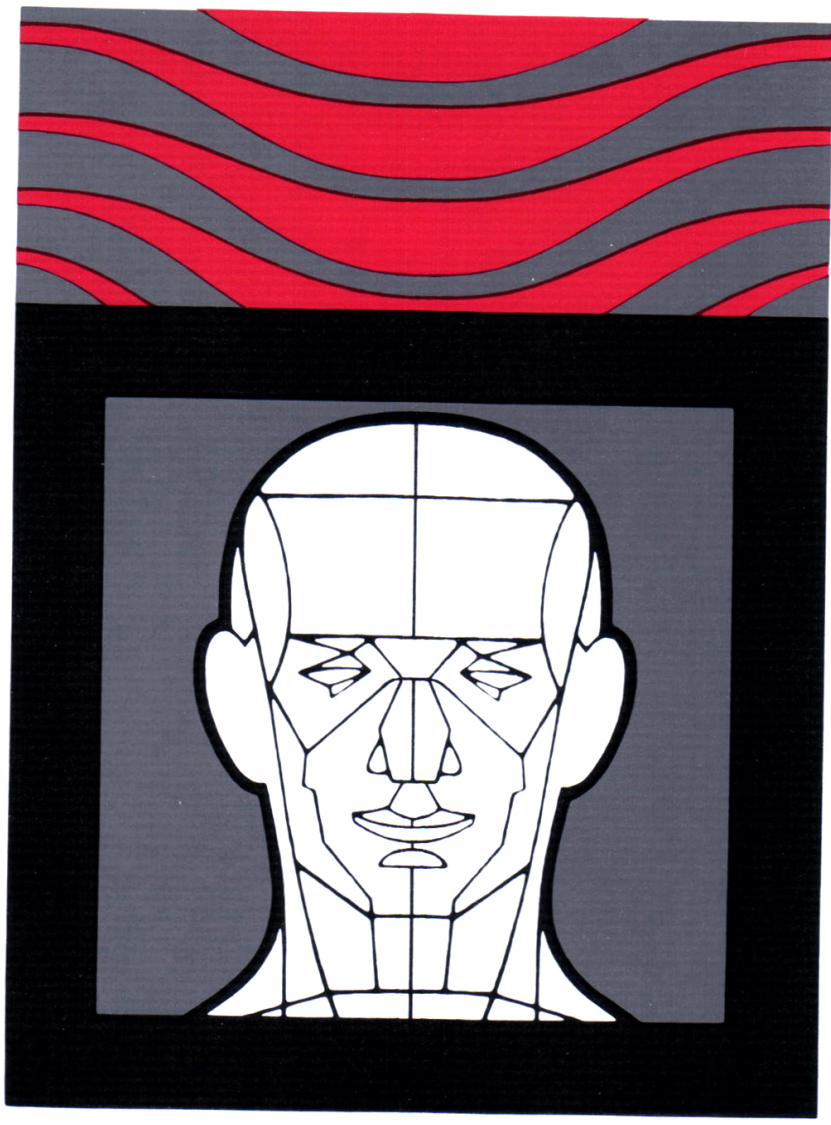

\section{Sandomigran}

maintenance therapy

helps prevent recurrent headaches

Taken daily, Sandomigran can reduce the frequency, severity and duration of vascular or mixed headaches. ${ }^{1-3}$ In fact, Sandomigran has suppressed throbbing headaches altogether in many patients. ${ }^{3-5}$
Double-strength DS tablet improves compliance

Patients have fewer tablets to take and find it easier to comply with maintenance therapy. The DS tablet also simplifies dosage: with a half-life of 23 hours, ${ }^{6}$

treatment can be initiated h.s.; the dosage may be increased to a maximum of 6 DS tablets a day in divided doses (see prescribing information).
Sandomigran DS for at least 4 weeks

Sandomigran DS must be taken daily for at least four weeks not to relieve headaches but to prevent them.

\section{HSandomigran ${ }^{\text {(i) }}$ DS 1 mg pizotyline}

Doesn't give recurrent throbbing headaches a second chance. 


\title{
THE ROYAL COLLEGE OF PHYSICIANS AND SURGEONS OF CANADA
}

\author{
with the co-operation of the Canadian Neurosurgical Society \\ announces
}

THE K.G. MCKENZIE MEMORIAL AWARDS

to honour the memory of

Canada's pioneer neurosurgeon

AWARD 1. A citation and prize of $\$ 100.00$ will be awarded for the best paper presented to the annual meeting of the Canadian Neurosurgical Society by a neurosurgical resident in which he is the principal author. The recipient, as well, will have his expenses, including Air Fare, Hotel Accommodation and Registration Fees, paid for as part of the Award.

AWARD 2. A grant-in-aid will be awarded to support a specific educational project which may include travel. (However, travel to regularly scheduled neurosurgical meetings is excluded.) The applicant must be a resident in training in a Canadian Neurosurgical Training Program, or if formal training is completed, within two years of having received certification in neurosurgery.

\section{APPLICATIONS FOR AWARD 1.}

Papers should be received by the chairman of the Awards Committee not later than January 15 . All papers received will be automatically forwarded to the program chairman for the annual meeting of the Canadian Congress of Neurological Sciences for further consideration. The successful candidate will be notified by April 1, and the awards will be presented at the annual meeting in June.

\section{APPLICATIONS FOR AWARD 2.}

Applicants should forward a comprehensive letter to the chairman of the Awards Committee by January 15 . The application should contain relevant personal information, a clear description of the educational project which is contemplated; and its purpose, and any supporting letters the applicant may wish to submit. The successful applicant will be notified by April 1.

\section{APPLICATIONS SHOULD BE SENT TO:}

Chairman

K.G. McKenzie Memorial Awards Committee

Room 2 - 113 Centennial Wing, Victoria General Hospital

HALIFAX, Nova Scotia 


\section{THE FRANCIS MCNAUGHTON AWARD}

The Francis McNaughton Award is awarded by the Canadian Neurological Society for the best paper submitted to the Canadian Congress of Neurological Sciences by a junior member of the society or a resident in a neurology training program. Full members of the society who have completed their clinical training and obtained certification in neurology within the past two years are also eligible to apply.

The work should be original and should not have been presented previously. Applicants need not be the sole author but should be primarily responsible for the work to be presented.

The award includes an honorarium of $\$ 200$, return air fare to the city of the congress and a suitably inscribed book prize.

In addition to the regular abstract for the congress, applicants should submit in triplicate an expanded abstract of approximately 2,000 words.

Applications should be submitted to:

Dr. William Pryse-Phillips

Health Sciences Centre

St. John's, Newfoundland

A1B 3V6

Deadline: February 15, 1983

\section{THE JASPER PRIZE IN CLINICAL NEUROPHYSIOLOGY}

The Jasper Prize is awarded by the Canadian Society of Clinical Neurophysiologists for the best original work based on clinical neurophysiology done by a resident or postdoctoral fellow.

The prize consists of an honorarium of $\$ 100$ plus return air fare to the congress.

Applications should be submitted to:

Dr. William Pryse-Phillips

Health Sciences Centre

St. John's, Newfoundland

A $1 B$ BV 6

Deadline: February 15, 1983. 